Research Paper

\title{
High Expression of Aldolase B Confers a Poor Prognosis for Rectal Cancer Patients Receiving Neoadjuvant Chemoradiotherapy
}

\author{
Yu-Feng Tian1, 2, Pei-Ling Hsieh³, Ching-Yih Lin4, 5, Ding-Ping Sun1,6, Ming-Jen Sheu, Ching-Chieh Yang7,
}

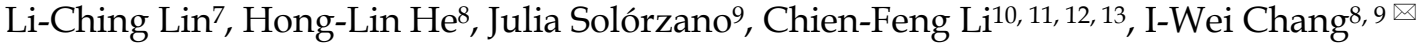

1. Division of General Surgery, Department of Surgery, Chi Mei Medical Center, Tainan, Taiwan;

2. Department of Health \& Nutrition, Chia Nan University of Pharmacy and Science, Tainan, Taiwan;

3. Department of Medical Image, Chi Mei Medical Center, Tainan, Taiwan;

4. Division of Gastroenterology and Hepatology, Department of Internal Medicine, Chi Mei Medical Center, Tainan, Taiwan;

5. Department of Leisure, Recreation, and Tourism Management, Southern Taiwan University of Science and Technology, Tainan, Taiwan

6. Department of Pharmacy, Chia Nan University of Pharmacy and Science, Tainan, Taiwan;

7. Department of Radiation Oncology, Chi-Mei Medical Center, Tainan, Taiwan;

8. Department of Pathology, E-DA Hospital, I-Shou University, Kaohsiung, Taiwan;

9. School of Medicine, I-Shou University, Kaohsiung, Taiwan;

10. Department of Pathology, Chi Mei Medical Center, Tainan, Taiwan;

11. National Institute of Cancer Research, National Health Research Institutes, Tainan, Taiwan;

12. Department of Biotechnology, Southern Taiwan University of Science and Technology, Tainan, Taiwan;

13. Institute of Clinical Medicine, Kaohsiung Medical University, Kaohsiung, Taiwan.

$\triangle$ Corresponding author: I-Wei Chang, M.D., Ph.D., Department of Pathology, E-DA Hospital, 1, Yi-Da Rd., Yan-Chao Dist., Kaohsiung, Taiwan. E-mail: b8701079@gmail.com TEL: +886-7-6150011 ext. 2620 FAX: +886-7-6150974

(c) Ivyspring International Publisher. This is an open access article distributed under the terms of the Creative Commons Attribution (CC BY-NC) license (https://creativecommons.org/licenses/by-nc/4.0/). See http://ivyspring.com/terms for full terms and conditions.

Received: 2016.11.03; Accepted: 2017.01.30; Published: 2017.04.09

\begin{abstract}
Background: Colorectal cancer is the third most common cancer in both sex worldwide and it is also the fourth most common cause of cancer mortality. For rectal cancer, neoadjuvant concurrent chemoradiotherapy (CCRT) followed by radical proctectomy is gold standard treatment for patients with stage II/III rectal cancer. By data mining a documented database of rectal cancer transcriptome (GSE35452) from Gene Expression Omnibus, National Center of Biotechnology Information, we recognized that $A L D O B$ was the most significantly up-regulated transcript among those related to glycolysis (GO: 0006096). Hence, we analyzed the clinicopathological correlation and prognostic effect of ALDOB protein (Aldolase B), which encoded by ALDOB gene.

Methods: ALDOB immunostain was performed in 172 rectal adenocarcinomas treated with preoperative chemoradiotherapy followed by radical surgery, which were divided into high- and low-expression groups. Furthermore, statistical analyses were examined to correlate the relationship between ALDOB immunoreactivity and important clinical and pathological characteristics, as well as three survival indices: disease-specific survival (DSS), local recurrence-free survival (LRFS) and metastasis-free survival (MeFS).

Results: ALDOB (Aldolase B) over-expression was significantly associated with pre-CCRT and post-CCRT tumor advancement, lymphovascular invasion, perineural invasion and poor response to CCRT (all $P \leq .023$ ). In addition, ALDOB high expression was linked to adverse DSS, LRFS and MeFS in univariate analysis $(P \leq .0075)$ and also served as an independent prognosticator indicating dismal DSS and MeFS in multivariate analysis (hazard ratio $(H R)=3.462,95 \%$ confidence interval $(\mathrm{Cl})$ : 1.263-9.495; $\mathrm{HR}=2.846,95 \% \mathrm{Cl}: 1.190-6.808$, respectively).

Conclusion: ALDOB (Aldolase B) may play an imperative role in rectal cancer progression and responsiveness to neoadjuvant CCRT, and serve as a novel prognostic biomarker. Additional researches to clarify the molecular and biochemical pathways are essential for developing promising ALDOB-targeted therapies for patients with rectal cancers.
\end{abstract}

Key words: ALDOB, Aldolase B, CCRT, chemoradiotherapy, rectal cancer. 


\section{Introduction}

Colorectal cancer $(\mathrm{CRC})$ is ranked as the third most common malignancy in both sexes by incidence, approximately 1.36 million per year worldwide. It is more prevalent in developed countries [1]. The incidence rate also increased much in Taiwan in the decades, maybe attributed to change of habit to Western-style diet $[2,3]$. In the aspect of treatment strategies, there are difference between rectal cancer and colon cancer. For patients with rectal cancers invading through muscularis propria or metastasizing to regional lymph nodes, neoadjuvant concurrent chemoradiotherapy (CCRT) is gold standard in National Comprehensive Cancer Network (NCCN) Guidelines ${ }^{\circledR}$ [4]. In spite of the introduction of new strategies of therapy for the patients, CRCs are usually diagnosed in middle- or late-stage and still the fourth most common cause of cancer-related mortality, after lung, liver and gastric cancers $[1,5]$. Hence, to find new prognostic factors and potential targets for treatment of CRC is imperative for scientists.

Deregulation of cellular energetics is one of the hallmarks of cancers [6]. Otto Heinrich Warburg, a German physiologist and laureate of Nobel Prize in Physiology or Medicine, discovered that most malignant cells generate ATPs predominantly via glycolysis and lactic acid fermentation but not tricarboxylic acid (TCA) cycle $[7,8]$. This phenomenon is termed "Warburg effect", and have been long-term applied to detect malignancy [9]. That is positron emission tomography (PET), where fluorine-18-fludeoxyglucose (18F-FDG), a glucose analog, is uptaken by tissue with high glucose demand, such as cancer [10]. However, the genes associated with glycolysis have yet been comprehensively studied in human rectal cancer. Therefore, we analyzed a previously published transcriptomic dataset of rectal cancer (GSE35453) and focused on genes associated with glycolysis (GO:0006096). As a result, $A L D O B$ was identified as the most significantly up-regulated gene.

$A L D O B$ gene encodes Aldolase B (ALDOB protein), A.K.A. fructose-bisphosphate aldolase B, which plays an essential role in glycolysis and gluconeogenesis [11]. Aldolase $B$, one of three isoenzyme of human aldolase, which normally exists in liver, kidney and intestine [12]. The aberrant expression of Aldolase B has been investigated in hepatocellular carcinoma [13-16], gastric cancer [17] and pseudomyxoma peritonei [18]. To the best of our knowledge, however, the clinical significance of Aldolase B has yet been systemically studied in CRCs. Therefore, we conducted the following research.
Materials and Methods

\section{Data mining of transcriptomic dataset of rectal cancers to identify the most up-regulated gene}

A published transcriptomic database (GSE35452), composed of 46 patients of rectal cancer doctored with preoperative chemoradiotherapy from Gene Expression Omnibus, National Center for Biotechnology Information (GEO, NCBI, Bethesda, MD, USA), was selected for research. The tumors were divided into "responder" and "non-responder" according to the response to neoadjuvant CCRT. We downloaded the raw .cel file and performed comparative analysis without filtering or preselection by the software--Nexus Expression 3 (BioDiscovery, El Segundo, CA, USA). Under supervision, we examined the statistical significance of each transcript by comparing responder and non-responder, focusing on the genes linked to glycolysis (GO:0006096). The transcripts with expression fold change $> \pm .1 \log _{2}$ ratio and $P$-value $<.01$ were selected for additional evaluation

\section{Study cohort of patients and specimens}

The Institutional Review Board of Chi-Mei Medical Center approved this study. Totally 172 patients with primary rectal adenocarcinoma between 1998 and 2004 were enrolled from Chi-Mei Medical Center. All patients received preoperative chemoradiotherapy followed by radical proctectomy. The initial clinical staging was determined by endoscopic ultrasound (EUS) and abdominopelvic computed tomography (CT). Cases with distant metastasis at primary diagnosis (cM1), screened by chest plain film and abdominopelvic CT, were excluded. The clinical information was retrieved from the archives of medical records. The details of patient selection and the protocol of treatment were the same as preceding description [19].

\section{Histopathological evaluation, immunohistochemical study and assessment of immunoreactivity}

Post-CCRT staging was based on pathological examination of radical proctectomy according to $7^{\text {th }}$ edition of American Joint Committee on Cancer (AJCC) cancer staging system [20]. The grading system of tumor regression after preoperative chemoradiotherapy was evaluated in accordance with the description of Dworak et al. [21]. The method of immunohistochemistry is the same as that we reported previously [22-25]. Briefly speaking, paraffin-embedded tissue of pre-CCRT tumor biopsy specimens were administered the routine procedure 
of deparaffinization, rehydration, and epitope retrieval. Subsequently, the tissue sections were proceeded to incubation with primary antibody against ALDOB (1:100, clone EPR3137, Abcam, Cambridge, United Kingdom) for one hour. Normal liver tissues with and without incubation of ALDOB antibody were run parallel as positive and negative control, respectively. We assessed the expression of ALDOB protein by combination of the intensity and percentage of immunoreactivity in the cytoplasm of tumor cells to produce an $\mathrm{H}$-score. The equation is shown below: H-score $=\Sigma \mathrm{Pi}(\mathrm{i}+1)$, in which $\mathrm{Pi}$ symbolizes the percentage of stained tumor cells $(0 \%-100 \%)$ and $i$ symbolizes the intensity of immunostain (0-3+).

\section{Statistical tests}

IBM SPSS Statistics software, Version 22.0 (IBM Corporation, Armonk, NY, USA) was used for statistical analyses. After separating the study cohort into high- and low-expression of ALDOB (Aldolase B) by the median $\mathrm{H}$-score of ALDOB immunoreactivity, Pearson's $X^{2}$ test was used for the relationship between ALDOB immunostaining and categorical important clinical and pathological parameters. Three prognostic indices-disease-specific survival (DSS), locoregional recurrent-free survival (LRFS) and metastasis-free survival (MeFS) were calculated from the days of tumor excision to those of events occurred. Kaplan-Meier survival curves compared with log-rank test was used in univariate survival analysis. Parameters with statistical significance in univariate analyses were enrolled in multivariate ones, for which, Cox model was used. For all analyses, only $P$ value $<.05$ was considered as statistically significant under two-tailed tests.

\section{Results}

\section{ALDOB recognized as the most significantly up-regulated gene among those belonging to glycolysis (GO:0006096)}

In the public transcriptomic dataset of rectal cancer (GSE35452) from GEO, NCBI, 24 out of 46 $(52.2 \%)$ patients revealed response to preoperative CCRT (responder), the rest $22(47.8 \%)$ patients showed resistance to preoperative CCRT (non-responder). Six probes covering three transcripts associated with glycolysis (GO:0006096) were found. Of these, four probes covering $A L D O B$ transcript and two probes covering PGK1 and $L D H B$ transcripts exhibited significant up- and down-regulation in non-responders than in responders, respectively (Fig. 1). The $\log _{2}$ ratios of up-regulated $A L D O B$ mRNA by comparison between non-responders and responders were between 0.3209 and $1.1475(P \leq .0098$, Table 1).

\section{Clinical and pathological characteristics of patients with rectal adenocarcinomas}

As shown in Table 2, most of our patient cohort of rectal adenocarcinoma was male $(62.8 \%, \mathrm{n}=108)$ and less than 70 years old $(61.6 \%, n=106)$. The invasive depth of $47.1 \%$ tumors $(n=81)$ at pre-CCRT clinical tumor staging was limited to muscularis propria (cT1-2), and $52.9 \%(\mathrm{n}=91)$ was beyond the muscularis propria (cT3-4). Forty-seven patients $(27.3 \%)$ had nodal metastasis at pre-CCRT clinical tumor staging, and 125 patients $(72.7 \%)$ didn't. The invasive depth of half tumors $(n=86)$ at post-CCRT pathological tumor staging was limited to muscularis propria (ypT0-2), and the other half $(\mathrm{n}=86)$ was beyond the muscularis propria (ypT3-4). Forty-nine patients $(28.5 \%)$ had nodal metastasis at post-CCRT pathological tumor staging, and 123 patients (71.5\%) didn't. Lymphovascular and perineural invasion were observed in $15(8.7 \%)$ and 5 (2.9\%) tumors, respectively. The tumor response to neoadjuvant CCRT varied from grade $0-1(n=37,21.5 \%)$, grade $2-3$ $(n=118,68.6 \%)$ and grade $4(n=17,9.9 \%)$.

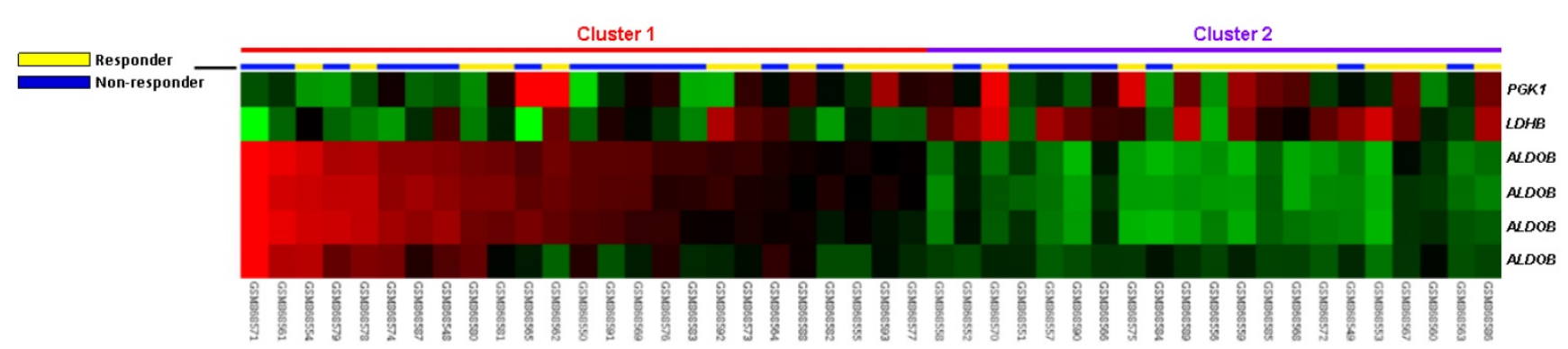

Fig. 1. Analysis of gene expression in rectal cancers with preoperative chemoradiation therapy by using a published transcriptome dataset (GSE35452). Conducting a clustering analysis of genes by focusing on glycolysis (GO:0006096) revealed that ALDOB is the most significantly up-regulated genes in non-responder comparing with responder. Tumors classified as responder (yellow) or non-responder (blue) are illustrated at the top of the heat map, and the up-regulation and down-regulation of gene expression are represented as a continuum of brightness of red or green, respectively. Tumors with unchanged transcriptional level are in black. 
Table 1. Significantly deregulated genes associated with glycolysis (GO:0006096) based on CCRT response in rectal cancer

\begin{tabular}{|c|c|c|c|c|c|c|}
\hline Probe & $\begin{array}{l}\text { Comparison } \\
\log _{2} \text { ratio }\end{array}$ & $\begin{array}{l}\text { Comparis } \\
\text { on } P \text {-value }\end{array}$ & $\begin{array}{l}\text { Gene } \\
\text { Symbol }\end{array}$ & Gene Name & Biological Process & Molecular Function \\
\hline $\begin{array}{l}21723 \\
\text { 8_s_at }\end{array}$ & 1.1475 & 0.0002 & $\begin{array}{l}A L D O \\
B\end{array}$ & $\begin{array}{l}\text { aldolase B; } \\
\text { fructose-bisph } \\
\text { osphate }\end{array}$ & $\begin{array}{l}\text { fructose metabolic process, glycolysis, metabolic } \\
\text { process }\end{array}$ & $\begin{array}{l}\text { catalytic activity, fructose-bisphosphate aldolase } \\
\text { activity, lyase activity }\end{array}$ \\
\hline $\begin{array}{l}20470 \\
\text { 5_x_at }\end{array}$ & 1.1092 & $<0.0001$ & $\begin{array}{l}A L D O \\
B\end{array}$ & $\begin{array}{l}\text { aldolase B; } \\
\text { fructose-bisph } \\
\text { osphate }\end{array}$ & $\begin{array}{l}\text { fructose metabolic process, glycolysis, metabolic } \\
\text { process }\end{array}$ & $\begin{array}{l}\text { catalytic activity, fructose-bisphosphate aldolase } \\
\text { activity, lyase activity }\end{array}$ \\
\hline $\begin{array}{l}21135 \\
\text { 7_s_at }\end{array}$ & 0.9714 & 0.0004 & $\begin{array}{l}A L D O \\
B\end{array}$ & $\begin{array}{l}\text { aldolase B; } \\
\text { fructose-bisph } \\
\text { osphate }\end{array}$ & $\begin{array}{l}\text { fructose metabolic process, glycolysis, metabolic } \\
\text { process }\end{array}$ & $\begin{array}{l}\text { catalytic activity, fructose-bisphosphate aldolase } \\
\text { activity, lyase activity }\end{array}$ \\
\hline $\begin{array}{l}20470 \\
\text { 4_s_at }\end{array}$ & 0.3209 & 0.0098 & $\begin{array}{l}A L D O \\
B\end{array}$ & $\begin{array}{l}\text { aldolase B; } \\
\text { fructose-bisph } \\
\text { osphate }\end{array}$ & $\begin{array}{l}\text { fructose metabolic process, glycolysis, metabolic } \\
\text { process }\end{array}$ & $\begin{array}{l}\text { catalytic activity, fructose-bisphosphate aldolase } \\
\text { activity, lyase activity }\end{array}$ \\
\hline $\begin{array}{l}\text { 15583 } \\
\text { 65_at }\end{array}$ & -0.4005 & 0.0049 & PGK1 & $\begin{array}{l}\text { phosphoglyce } \\
\text { rate kinase } 1\end{array}$ & glycolysis, phosphorylation & $\begin{array}{l}\text { ATP binding, kinase activity, nucleotide binding, } \\
\text { phosphoglycerate kinase activity, transferase } \\
\text { activity }\end{array}$ \\
\hline $\begin{array}{l}21356 \\
4 \_x \_a t\end{array}$ & -0.3606 & 0.0045 & $L D H B$ & $\begin{array}{l}\text { lactate } \\
\text { dehydrogenas } \\
\text { e B }\end{array}$ & $\begin{array}{l}\text { anaerobic glycolysis, anti-apoptosis, apoptosis, } \\
\text { cellular carbohydrate metabolic process, glycolysis, } \\
\text { protein folding, tricarboxylic acid cycle } \\
\text { intermediate metabolic process }\end{array}$ & $\begin{array}{l}\text { Hsp70/Hsc70 protein regulator activity, L-lactate } \\
\text { dehydrogenase activity, oxidoreductase activity, } \\
\text { oxidoreductase activity; acting on the } \mathrm{CH}-\mathrm{OH} \\
\text { group of donors; NAD or NADP as acceptor, } \\
\text { protein binding }\end{array}$ \\
\hline
\end{tabular}

Table 2. Relationships between ALDOB expression and clinicopathological factors in rectal cancer patients receiving preoperative CCRT

\begin{tabular}{|c|c|c|c|c|c|}
\hline \multirow[t]{2}{*}{ Parameter } & & \multirow[t]{2}{*}{ No. } & \multicolumn{2}{|c|}{ ALDOB Expression } & \multirow[t]{2}{*}{$P$-value } \\
\hline & & & Low Exp. & High Exp. & \\
\hline \multirow[t]{2}{*}{ Gender } & Male & 108 & 55 & 53 & 0.752 \\
\hline & Female & 64 & 31 & 33 & \\
\hline \multirow[t]{2}{*}{ Age } & $<70$ & 106 & 52 & 54 & 0.754 \\
\hline & $\geq 70$ & 66 & 34 & 32 & \\
\hline \multirow[t]{2}{*}{ Pre-CCRT cT stage } & cT1-2 & 81 & 43 & 38 & 0.445 \\
\hline & cT3-4 & 91 & 43 & 48 & \\
\hline \multirow[t]{2}{*}{ Pre-CCRT cN stage } & cN0 & 125 & 72 & 53 & $0.001^{*}$ \\
\hline & cN1-2 & 47 & 14 & 33 & \\
\hline \multirow[t]{3}{*}{ Pre-CCRT CEA } & $\leq 5$ & 114 & 63 & 51 & 0.053 \\
\hline & $\mathrm{ng} / \mathrm{ml}$ & & & & \\
\hline & $\begin{array}{l}>5 \\
\mathrm{ng} / \mathrm{ml}\end{array}$ & 58 & 23 & 35 & \\
\hline \multirow[t]{2}{*}{ Post-CCRT pT stage } & pT0-2 & 86 & 53 & 33 & $0.002^{*}$ \\
\hline & pT3-4 & 86 & 33 & 53 & \\
\hline \multirow[t]{2}{*}{ Post-CCRT pN stage } & $\mathrm{pN} 0$ & 123 & 76 & 47 & $<0.001^{*}$ \\
\hline & pN1-2 & 49 & 10 & 39 & \\
\hline \multirow[t]{2}{*}{ Lymphovascular invasion } & Absent & 157 & 83 & 74 & $0.015^{*}$ \\
\hline & Present & 15 & 3 & 12 & \\
\hline \multirow{2}{*}{ Perineural invasion } & Absent & 167 & 86 & 81 & $0.023^{*}$ \\
\hline & Present & 5 & 0 & 5 & \\
\hline \multirow[t]{3}{*}{ Tumor regression grade } & $\begin{array}{l}\text { Grade } \\
0-1\end{array}$ & 37 & 12 & 25 & $<0.001^{*}$ \\
\hline & $\begin{array}{l}\text { Grade } \\
2-3\end{array}$ & 118 & 59 & 59 & \\
\hline & Grade 4 & 17 & 15 & 2 & \\
\hline
\end{tabular}

*, statistically significant

\section{Association between ALDOB immunoreactivity and clinical and pathological variables}

After dichotomizing the study cohort into ALDOB high- and low-expression groups with cutoff point of median H-score (195), we applied Pearson's $X^{2}$ test to examine the relationship between ALDOB immunostaining and variable clinical and pathological parameters. As demonstrated in Table 2, ALDOB overexpression was significantly associated with more advanced post-CCRT pT status $(P=.002)$, both positive pre- and post-CCRT nodal metastasis $(P$ $\leq .001$ for both), lymphovascular invasion $(P=.015)$, perineural invasion $(P=.023)$ and poor response to neoadjuvant CCRT (Fig. $2, P<.001$ ).

\section{Survival analyses for patients with rectal adenocarcinomas}

In univariate analyses (Table 3), more advanced post-CCRT tumor invasiveness and lower tumor regression grade were significantly correlated with shorter DSS, LRFS and MeFS intervals $(P \leq .009$ for all). Higher pre-CCRT serum CEA level $(>5 \mathrm{ng} / \mathrm{ml})$ and presence of lymphovascular invasion were negatively associated with DSS and LRFS to statistical significance $(P \leq .0216$ for all). Positive pre-CCRT nodal status was significantly associated with adverse LRFS only $(P=.007)$.

In multivariate analyses (Table 4), tumor regression grade was an independent prognosticator for DSS (hazard ratio $(\mathrm{HR})=2.101,95 \%$ confidence interval (CI): 1.001-4.425), LRFS (HR $=2.762,95 \% \mathrm{CI}$ : 1.241-6.173) and MeFS $(\mathrm{HR}=2.242,95 \% \mathrm{CI}$ : 1.092-4.587). Lymphovascular invasion and high pre-CCRT serum CEA level were independent prognostic factor for LRFS only $(\mathrm{HR}=3.662,95 \% \mathrm{CI}$ : 1.191-11.264; $\mathrm{HR}=2.496,95 \%$ CI: 1.061-5.876, respectively).

\section{Prognostic significance of ALDOB overexpression in patients with rectal adenocarcinomas}

High immunoreactivity of ALDOB protein (Aldolase B) was significantly correlated with poor 
DSS, LRFS and MeFS in univariate analyses $(P \leq .0075$ for all, Table 3 and Fig.3). High expression of ALDOB still independently predicted worse DSS and MeFS in multivariate analyses $(\mathrm{HR}=3.462, \quad 95 \%$ CI: 1.263-9.495; $\mathrm{HR}=2.846,95 \%$ CI: 1.190-6.808, respectively) (Table 4 ).
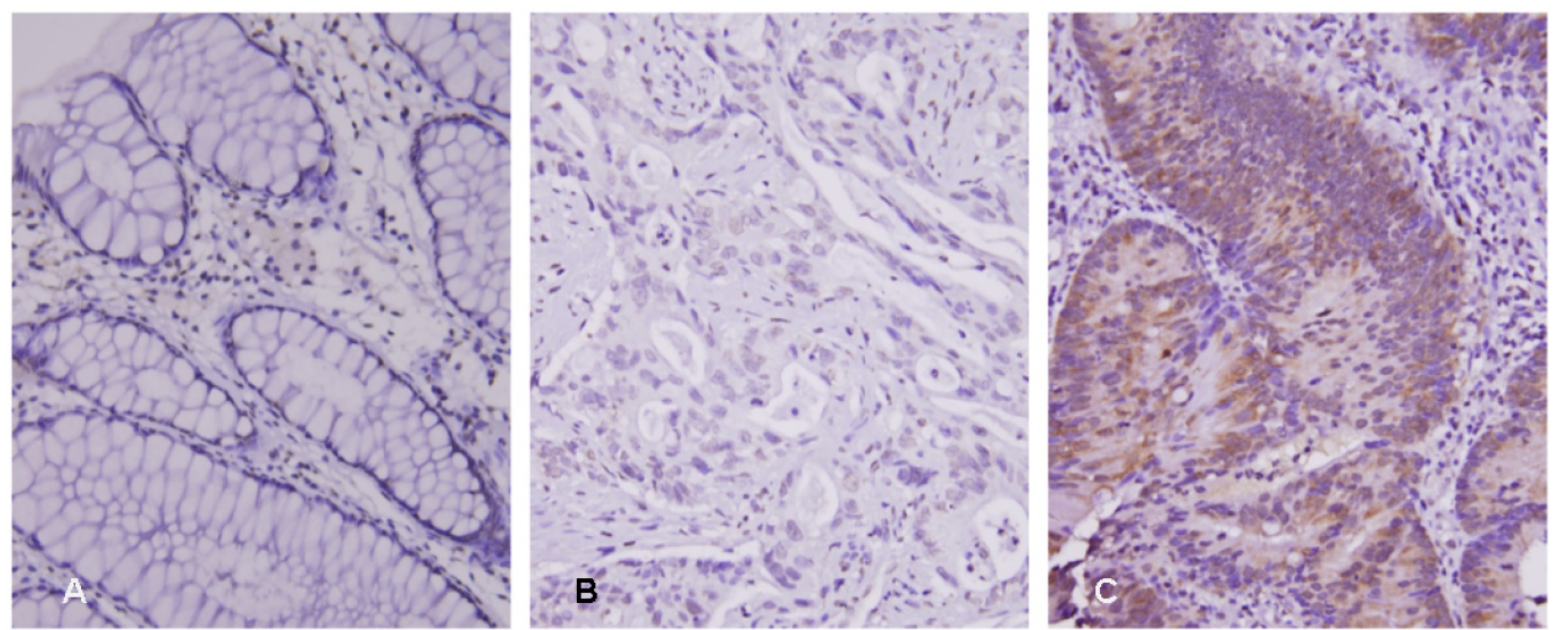

Fig. 2. ALDOB (Aldolase B) immunostain on representative sections showed (A) no expression in normal colonic mucosa, (B) low ALDOB immunoreactivity in tumors with high tumor regression grade after preoperative chemoradiation therapy, and (C) high ALDOB immunoreactivity in tumors with low tumor regression grade.

Table 3. Univariate log-rank analysis for important clinicopathological variables and ALDOB expression

\begin{tabular}{|c|c|c|c|c|c|c|c|c|}
\hline \multirow[t]{2}{*}{ Parameter } & & \multirow[t]{2}{*}{ No. of case } & \multicolumn{2}{|c|}{ Disease-specific survival } & \multicolumn{2}{|c|}{$\begin{array}{l}\text { Local recurrence-free } \\
\text { survival }\end{array}$} & \multicolumn{2}{|c|}{ Metastasis-free survival } \\
\hline & & & No. of event & $P$ & No. of event & $P$ & No. of event & $P$ \\
\hline \multirow[t]{2}{*}{ Gender } & Male & 108 & 20 & 0.9026 & 7 & 0.2250 & 17 & 0.3520 \\
\hline & Female & 64 & 11 & & 20 & & 14 & \\
\hline \multirow[t]{2}{*}{ Age } & $<70$ & 106 & 19 & 0.8540 & 18 & 0.6615 & 20 & 0.7427 \\
\hline & $\geq 70$ & 66 & 12 & & 9 & & 11 & \\
\hline \multirow[t]{2}{*}{ Pre-CCRT cT stage } & cT1-2 & 81 & 10 & 0.0776 & 10 & 0.2261 & 11 & 0.1745 \\
\hline & cT3-4 & 91 & 21 & & 17 & & 20 & \\
\hline \multirow[t]{2}{*}{ Pre-CCRT cN stage } & $\mathrm{cN} 0$ & 125 & 19 & 0.0711 & 15 & $0.0070^{*}$ & 19 & 0.0973 \\
\hline & cN1-2 & 47 & 21 & & 12 & & 12 & \\
\hline \multirow[t]{2}{*}{ Pre-CCRT CEA } & $\leq 5 \mathrm{ng} / \mathrm{ml}$ & 114 & 15 & $0.0216^{*}$ & 13 & $0.0179^{*}$ & 17 & 0.1460 \\
\hline & $>5 \mathrm{ng} / \mathrm{ml}$ & 58 & 16 & & 14 & & 14 & \\
\hline \multirow[t]{2}{*}{ Post-CCRT pT stage } & pT0-2 & 86 & 7 & $0.0006^{*}$ & 7 & $0.0040^{*}$ & 8 & $0.0033^{*}$ \\
\hline & рТ3-4 & 86 & 24 & & 20 & & 23 & \\
\hline \multirow[t]{2}{*}{ Post-CCRT pN stage } & pN0 & 123 & 21 & 0.5998 & 16 & 0.1320 & 20 & 0.4634 \\
\hline & pN1-2 & 49 & 10 & & 11 & & 11 & \\
\hline \multirow[t]{2}{*}{ Lymphovascular invasion } & Absent & 157 & 25 & $0.0184^{*}$ & 21 & $0.0028^{*}$ & 27 & 0.4470 \\
\hline & Present & 15 & 6 & & 6 & & 4 & \\
\hline \multirow[t]{2}{*}{ Perineural invasion } & Absent & 167 & 29 & 0.2559 & 25 & 0.0940 & 30 & 0.9083 \\
\hline & Present & 5 & 2 & & 2 & & 1 & \\
\hline \multirow[t]{3}{*}{ Tumor regression grade } & Grade $0-1$ & 37 & 13 & $0.0038^{*}$ & 10 & $0.0090^{*}$ & 14 & $0.0006^{*}$ \\
\hline & Grade 2-3 & 118 & 17 & & 17 & & 16 & \\
\hline & Grade 4 & 17 & 1 & & 0 & & 1 & \\
\hline \multirow[t]{2}{*}{ ALDOB expression } & Low Exp. & 86 & 5 & $<0.0001^{*}$ & 8 & $0.0075^{*}$ & 7 & $0.0005^{\star}$ \\
\hline & High Exp. & 86 & 26 & & 19 & & 24 & \\
\hline
\end{tabular}

*, statistically significant

Table 4. Multivariate survival analysis

\begin{tabular}{|c|c|c|c|c|c|c|c|c|c|}
\hline \multirow[t]{2}{*}{ Parameter } & \multicolumn{3}{|c|}{ Disease-specific survival } & \multicolumn{3}{|c|}{ Local recurrence-free survival } & \multicolumn{3}{|c|}{ Metastasis-free survival } \\
\hline & HR & $95 \% \mathrm{CI}$ & $P$ & HR & $95 \% \mathrm{CI}$ & $P$ & HR & $95 \% \mathrm{CI}$ & $P$ \\
\hline Tumor regression grade & 2.101 & $1.001-4.425$ & $0.050^{*}$ & 2.762 & $1.241-6.173$ & $0.013^{*}$ & 2.242 & $1.092-4.587$ & $0.028^{*}$ \\
\hline ALDOB expression & 3.462 & $1.263-9.495$ & $0.016^{*}$ & 1.372 & $0.550-3.422$ & 0.498 & 2.846 & $1.190-6.808$ & $0.019^{*}$ \\
\hline Lymphovascular invasion & 2.401 & $0.896-6.435$ & 0.082 & 3.662 & $1.191-11.264$ & $0.024^{*}$ & - & - & - \\
\hline Pre-CCRT CEA & 1.971 & $0.930-4.177$ & 0.076 & 2.496 & $1.061-5.876$ & $0.036^{*}$ & & & \\
\hline Post-CCRT pT stage & 1.882 & $0.761-4.658$ & 0.171 & 1.579 & $0.627-3.978$ & 0.333 & 1.819 & $0.766-4.321$ & 0.175 \\
\hline Pre-CCRT cN stage & - & - & - & 1.534 & $0.643-3.660$ & 0.845 & - & - & - \\
\hline
\end{tabular}

$\mathrm{HR}$, hazard ratio; $\mathrm{CI}$, confidence interval; *, statistically significant 

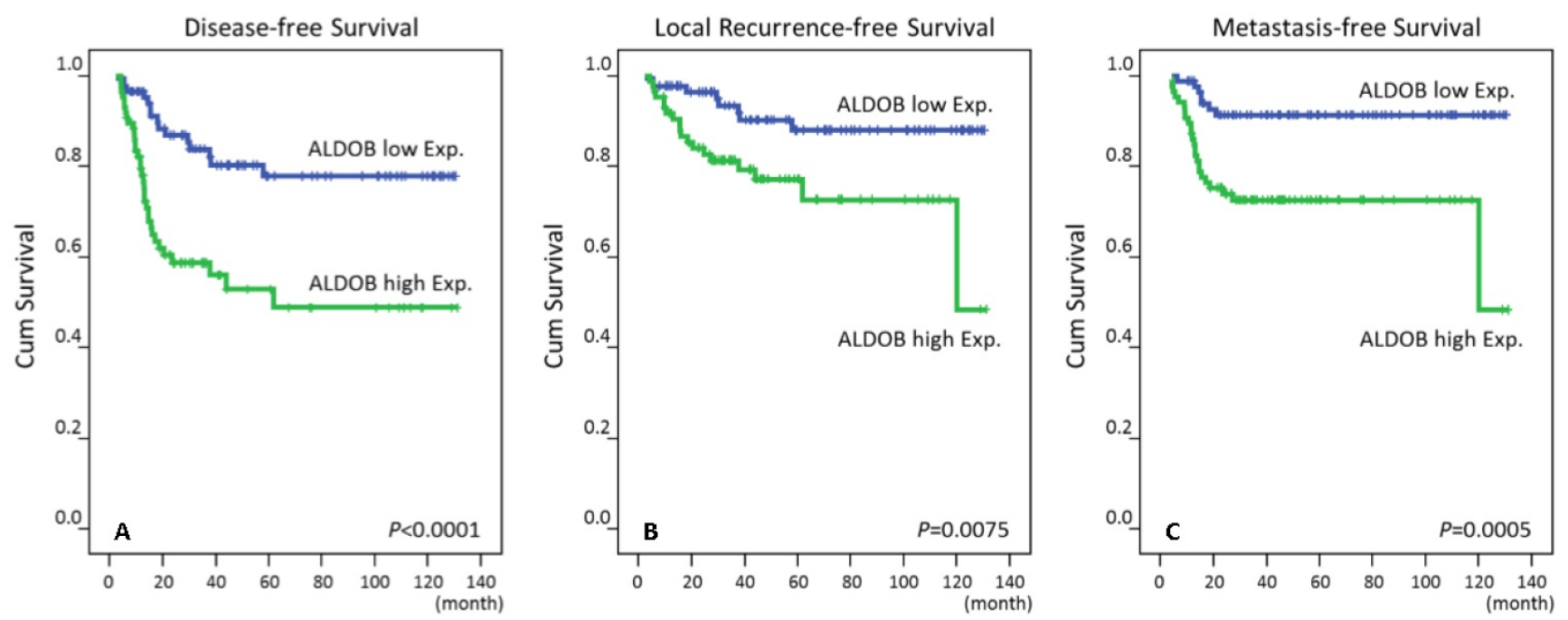

Fig. 3. Kaplan-Meier survival curves demonstrated significant prognostic impact of ALDOB expression on disease-specific survival ( $P<.0001)$, local recurrence-free survival $(P=.0075)$ and metastasis-free survival $(P=.0005)$.

\section{Discussion}

For patients with rectal cancers, the introduction of neoadjuvant CCRT for resectable tumors not only enhances the survival rates, but also augments the possibility of curative and/or sphincter-preserving resection, as a result of down-staging of the cancer. In two important randomized controlled studies, preoperative chemoradiotherapy improved survival rates for patients with rectal cancers, which invaded through muscularis propria (cT3-4) or combined with nodal metastasis (stage II/III) [26, 27]. Although some authors promoted the "Watch and Wait Protocol" for rectal cancers with complete response to neoadjuvant chemoradiation therapy for improving the life quality of patients [28], nowadays, neoadjuvant CCRT followed by radical proctectomy is still gold standard treatment for patients with rectal cancers of clinical stage II and III [4].

Aldolase is an enzyme catabolize fructose 1,6-bisphosphate into dihydroxyacetone phosphate and glyceraldehyde 3-phosphate in the glycolysis pathway. Therefore, aldolase is also termed fructose-bisphosphate aldolase [11]. In vertebrates, there are three isoenzymes in the Aldolase family. Aldolase A (ALDOA) is predominantly found in the muscle tissue and erythrocytes; Aldolase B (ALDOB) in the liver, kidney an intestine; Aldolase C (ALDOC) in the central nervous system [12, 29]. Over-expression of all three isoenzymes positively regulated the canonical Wnt/ $\beta$-catenin signaling pathway, a common pathway involved in carcinogenesis of CRC (30). The result indicated that all isoforms of Aldoase might serve as an oncogene in colorectal cancer [31]. As a key enzyme involving in glycolysis and gluconeogenesis, three isoenzymes had been investigated in cancers. Among them, most researches about Aldolase B (ALDOB) were studied in hepatocellular carcinoma. Firstly, the serum level of Aldolase B tended to be slightly elevated in patients with hepatocellular carcinoma (HCC) [32]. Nevertheless, down-regulation of $A L D O B$ gene or Aldolase $B$ protein were frequently observed in HCC tissues [13, 14, 16, 33-35]. Furthermore, Aldolase B under-expression in HCC was significantly associated with adverse clinico-pathological characteristics and worse recurrence-free survival and overall survival in both univariate and multivariate analyses (all $P<.05$ ) [15]. By using HCC cell lines for in vitro and in vivo study in the same article, over-expression of Aldolase $\mathrm{B}$ was also negatively correlated with cell migration in vitro and occurrence of lung metastasis and intrahepatic metastasis, as well as the numbers of circulating tumor cells in vivo [15]. On the contrary, up-regulation and over-expression of $A L D O B$ gene and Aldolase $B$ protein were detected in human tissue of pseuomyxoma peritonei (PMP) [18]. The discrepancy may reflect the different biochemical statuses of the same molecules in different microenvironment of each cancer. In HCCs, the metabolic pathway of energy utilization probably changes, where Aldolase A over-expression was observed along with under-expression of Aldolase B $[13,15]$. Over-expression of Aldolase B in human PMP might indicate the similar carcinogenetic processes, at least in certain aspects, between PMP and CRC, while the genetic alterations of PMP do overlap with those of CRC [36].

Concerning about the relationship between glycolytic enzymes and sensitivity of tumor to 
radiotherapy and chemotherapy, several studies reported it. Warburg effect was firstly found to be implicated in resistance to irradiation and chemotherapy [37, 38]. After that, Moeller et al. observed that ionizing radiation induced reoxygenation, which caused oxidative stress and radioresistance effects via upregulation of the transcription factor - hypoxia inducible factor 1 (HIF-1) [39-40]. HIF-1 is known as a regulator of the majority of glycolytic enzymes [41]. In the current study, we demonstrated over-expression of Aldolase B, a key enzyme of glycolysis, was significantly associated with poor response to CCRT. Therefore, increase of glycolytic activity or glycolytic enzymes in cancer cells may be an indicator for resistance to radiotherapy and chemotherapy, maybe via upregulation of HIF-1.

In conclusion, we demonstrated the significantly negative correlation between over-expression of Aldolase B and clinical and pathological parameters, such as pre- and post-treatment disease advancement, lymphovascular and perineural invasion, and less responsiveness to neoadjuvant CCRT in rectal cancer. Furthermore, high expression of Aldolase B in rectal adenocarcinoma was not only significantly associated with shorter disease-specific, local recurrent-free and metastasis-free survival intervals in univariate analysis, but also an independent prognostic biomarker predicting lower disease-specific and metastasis-free survival rates. The results indicated Aldolase B (ALDOB), both a key enzyme in glycolysis and positive regulator of canonical Wnt/ $\beta$-catenin signaling pathway, could be an independent prognostic factor and even a potential target for new strategies of treatment for patients with rectal cancers. More investigations to clarify the detailed biological and molecular pathway of Aldolase B are necessary.

\section{Abbreviations}

CCRT: concurrent chemoradiotherapy; ALDOB: Aldolase B; EUS: endoscopic ultrasound; AJCC: American Joint Committee on Cancer; DSS: disease-specific survival; LRFS: local recurrence-free survival; MeFS: metastasis-free survival.

\section{Acknowledgements}

This study is supported by Chi-Mei Medical Center (CLFHR10534). This study was also supported by grants from Kaohsiung Medical University "Aim for the Top Universities" (KMU-TP104E31, KMU-TP104G00, KMU-TP104G01, KMU-TP104G04), the health and welfare surcharge of tobacco products, Ministry of Health and Welfare (MOHW105-TDU-B-212-134007) and E-DA Hospital (EDAHP105063 and EDAHS105003). The authors thank the BioBank and the Translational Research Laboratory of Human Cancers of Chi Mei Medical Center for technical supports.

\section{Competing Interests}

The authors have declared that no competing interest exists.

\section{References}

1. Ferlay J, Soerjomataram I, Dikshit R, et al. Cancer incidence and mortality worldwide: sources, methods and major patterns in GLOBOCAN 2012. Int J Cancer. 2015; 136: E359-86.

2. Yeh CC, Hsieh LL, Tang R, Chang-Chieh CR, Sung FC. Risk factors for colorectal cancer in Taiwan: a hospital-based case-control study. J Formos Med Assoc 2003; 102: 305-12.

3. Wu CY, Lin JT. The changing epidemiology of Asian digestive cancers: From etiologies and incidences to preventive strategies. Best Pract Res Clin Gastroenterol. 2015; 29: 843-53.

4. Benson AB 3rd, Venook AP, Bekaii-Saab T, et al. Rectal Cancer, Version 2.2015. J Natl Compr Canc Netw. 2015; 13: 719-28.

5. Quan Y, Xu M, Cui P, et al. Grainyhead-like 2 Promotes Tumor Growth and is Associated with Poor Prognosis in Colorectal Cancer. J Cancer. 2015; 6: 342-50.

6. Hanahan D, Weinberg RA. Hallmarks of cancer: the next generation. Cell. 2011; 144: 646-74.

7. Warburg O. On respiratory impairment in cancer cells. Science. 1956; 124: 269-70.

8. Warburg O. On the origin of cancer cells. Science. 1956; 123: 309-14.

9. Devic S. Warburg Effect - a Consequence or the Cause of Carcinogenesis? J Cancer. 2016; 7: 817-22.

10. Som P, Atkins HL, Bandoypadhyay D, et al. A fluorinated glucose analog, 2-fluoro-2-deoxy-D-glucose (F-18): nontoxic tracer for rapid tumor detection. J Nucl Med. 1980; 21: 670-5.

11. Garrett RH, Grisham CM. Biochemistry, 6th ed. Boston, USA: Cengage Learning; 2016.

12. Tolan DR, Niclas J, Bruce BD, Lebo RV. Evolutionary implications of the human aldolase-A, $-\mathrm{B},-\mathrm{C}$, and -pseudogene chromosome locations. Am J Hum Genet. 1987; 41: 907-24

13. Peng SY, Lai PL, Pan HW, Hsiao LP, Hsu HC. Aberrant expression of the glycolytic enzymes aldolase B and type II hexokinase in hepatocellular carcinoma are predictive markers for advanced stage, early recurrence and poor prognosis. Oncol Rep. 2008; 19: 1045-53.

14. Song H, Xia SL, Liao C, et al. Genes encoding Pir51, Beclin 1, RbAp48 and aldolase $\mathrm{b}$ are up or down-regulated in human primary hepatocellular carcinoma. World J Gastroenterol. 2004; 10: 509-13.

15. Tao QF, Yuan SX, Yang F, et al. Aldolase B inhibits metastasis through Ten-Eleven Translocation 1 and serves as a prognostic biomarker in hepatocellular carcinoma. Mol Cancer. 2015; 14: 170.

16. Wang $Y$, Kuramitsu $Y$, Takashima M, et al. Identification of four isoforms of aldolase B down-regulated in hepatocellular carcinoma tissues by means of two-dimensional Western blotting. In Vivo. 2011; 25: 881-6.

17. Asaka M, Kimura T, Nishikawa S, Miyazuki T, Alpert E. Decreased serum aldolase B levels in patients with malignant tumors. Cancer. 1988; 62: 2554-7.

18. Roberts DL, O'Dwyer ST, Stern PL, Renehan AG. Global gene expression in pseudomyxoma peritonei, with parallel development of two immortalized cell lines. Oncotarget. 2015; 6: 10786-800.

19. Lin CY, Lin CY, Chang IW, et al. Low thrombospondin 2 expression is predictive of low tumor regression after neoadjuvant chemoradiotherapy in rectal cancer. Am J Transl Res. 2015; 7: 2423-32.

20. Edge SB, Byrd DR, Compton CC, et al. AJCC Cancer Staging Manual, 7th ed. Berlin, Germany: Springer; 2011.

21. Dworak O, Keilholz L, Hoffmann A. Pathological features of rectal cancer after preoperative radiochemotherapy. Int J Colorectal Dis. 1997; 12: 19-23.

22. Chang IW, Li CF, Lin VC, et al. Prognostic Impact of Thrombospodin-2 (THBS2) Overexpression on Patients with Urothelial Carcinomas of Upper Urinary Tracts and Bladders. J Cancer. 2016; 7: 1541-9.

23. Chang IW, Lin VC, Wu WJ, et al. Complement Component 1, s Subcomponent Overexpression is an Independent Poor Prognostic Indicator in Patients with Urothelial Carcinomas of the Upper Urinary Tract and Urinary Bladder. J Cancer. 2016; 7: 1396-405.

24. Chang IW, Wang YH, Wu WJ, et al. Necdin Overexpression Predicts Poor Prognosis in Patients with Urothelial Carcinomas of the Upper Urinary Tract and Urinary Bladder. J Cancer. 2016; 7: 304-13.

25. Ma LJ, Wu WJ, Wang YH, et al. SPOCK1 Overexpression Confers a Poor Prognosis in Urothelial Carcinoma. J Cancer. 2016; 7: 467-76.

26. Roh MS, Colangelo LH, O'Connell MJ, et al. Preoperative multimodality therapy improves disease-free survival in patients with carcinoma of the rectum: NSABP R-03. J Clin Oncol. 2009; 27: 5124-30.

27. Sauer R, Becker H, Hohenberger W, et al. Preoperative versus postoperative chemoradiotherapy for rectal cancer. N Engl J Med. 2004; 351: 1731-40. 
28. Walker AS, Zwintscher NP, Johnson EK, et al. Future directions for monitoring treatment response in colorectal cancer. J Cancer. 2014; 5: 44-57.

29. Arakaki TL, Pezza JA, Cronin MA, et al. Structure of human brain fructose 1,6-(bis)phosphate aldolase: linking isozyme structure with function. Protein Sci. 2004; 13: 3077-84.

30. Qiu CZ, Wang MZ, Yu WS, et al. Correlation of GOLPH3 Gene with Wnt Signaling Pathway in Human Colon Cancer Cells. J Cancer. 2016; 7: 928-34.

31. Caspi M, Perry G, Skalka N, et al. Aldolase positively regulates of the canonical Wnt signaling pathway. Mol Cancer. 2014; 13: 164.

32. Asaka M, Miyazaki T, Hollinger FB, Alpert E. Human aldolase B serum levels: a marker of liver injury. Hepatology. 1984; 4: 531-5.

33. Lau WY, Lai PB, Leung MF, et al. Differential gene expression of hepatocellular carcinoma using cDNA microarray analysis. Oncol Res. 2000; 12: 59-69.

34. Kinoshita M, Miyata M. Underexpression of mRNA in human hepatocellular carcinoma focusing on eight loci. Hepatology. 2002; 36: 433-8.

35. Liu Z, Ma Y, Yang J, Qin H. Upregulated and downregulated proteins in hepatocellular carcinoma: a systematic review of proteomic profiling studies. OMICS. 2011; 15: 61-71

36. Alakus H, Babicky ML, Ghosh P, et al. Genome-wide mutational landscape of mucinous carcinomatosis peritonei of appendiceal origin. Genome Med. 2014; 6: 43 .

37. Khodarev NN, Beckett M, Labay E, et al. STAT1 is overexpressed in tumors selected for radioresistance and confers protection from radiation in transduced sensitive cells. Proc Natl Acad Sci U S A. 2004; 101: 1714-9.

38. Pitroda SP, Wakim BT, Sood RF, et al. STAT1-dependent expression of energy metabolic pathways links tumour growth and radioresistance to the Warburg effect. BMC Med. 2009; 7: 68.

39. Moeller BJ, Cao Y, Li CY, Dewhirst MW. Radiation activates HIF-1 to regulate vascular radiosensitivity in tumors: role of reoxygenation, free radicals, and stress granules. Cancer Cell. 2004; 5: 429-41.

40. Moeller BJ, Dreher MR, Rabbani ZN, et al. Pleiotropic effects of HIF-1 blockade on tumor radiosensitivity. Cancer Cell. 2005; 8: 99-110.

41. Semenza GL. Oxygen sensing, homeostasis, and disease. N Engl J Med. 2011; 365: 537-47. 